\title{
INTRA-TRACHEAL ANESTHESIA FROM THE STANDPOINT OF THE NOSE, THROAT AND ORAL SURGEON WI'TH A DESCRIPTION OF A NEW INSTRUMENT FOR CATHETERIZING THE TRACHEA.*
}

\author{
DR. HINNIY IF. JANIWAY, NEW YORK CITY.
}

The satisfactory manner in which intra-tracheal anesthesia for operations in the nasal, oral or laryngeal regions or even within the trachea or bronchi meets the requirements clemanded during such operations is deserving of special comment. 'The very multiplicity of methods of administering an anesthetic during nose and throat operations testifies to the presence of dissatisfaction with most of the methods in common use. This dissatisfaction is most apparent in the usual methods of anesthesia in which the anesthetic is inhaled from a cone. Under such conditions the surgeon can operate. only during the intervals when the cone is removed. The anesthesia can never be a smooth one, but is characterized by periods of more or less profound coma alternating with periods of partial return to consciousness. During the latter, there is often more or less struggling and, perhaps, coughing or retching. Often the operation must be discontinued at very critical periods, at times for instance, when the hemorrhage may not be entirely controlled. Operating under such conditions greatly increases the dangers and risks, and unnecessarily prolongs the operation. The diffictilty of preventing the inhalation of blood and mucus is great, and constant care and attention is necessary in order to prevent such a complication. When the patients are profoundly anesthetized asphyxia from the falling back of the tongue is frequently troublesome. Lane of London, who formerly used this method in connection with his cleft palate operations, has well remarked that anesthesia for oral operations demands the services of an expert anesthetist and one, preferably, who is accustomed to work with the operator.

A more useful method is intra-nasal or pharyngeal anesthesia. By this method the ether vapor may be conveyed to the patient through glass bulbs fitted into the anterior nares or by means of a catheter passing to the pharynx through the nose. Both these methods are much more satisfactory than the preceding. Their use permits of

*From the Department of Experimental Surgery of New Fork University and Bellevue Hospital Medical, College. 
a more even anesthesia and, especially when the catheter is used through the nose, of a much greater ease in preventing inhalation of mucous or blood. Neither method, however, is entirely satisfactory in this last respect. The blood and mucus within the mouth must be constantly sponged or. sucked out, the head must be kept well thrown back and frequently trouble is experienced because of the falling back of the tongue.

Many surgeons have resorted to rectal anesthesia in order to avoid the inconvenience of the proximity of the anesthetist and his apparatus during operation about the head. Rectal anesthesia, however, has never come into general use. Perhaps this is an unfair argument to use against it. Its administration, nevertheless, requires considerable skill and accurate dosage by it is somewhat

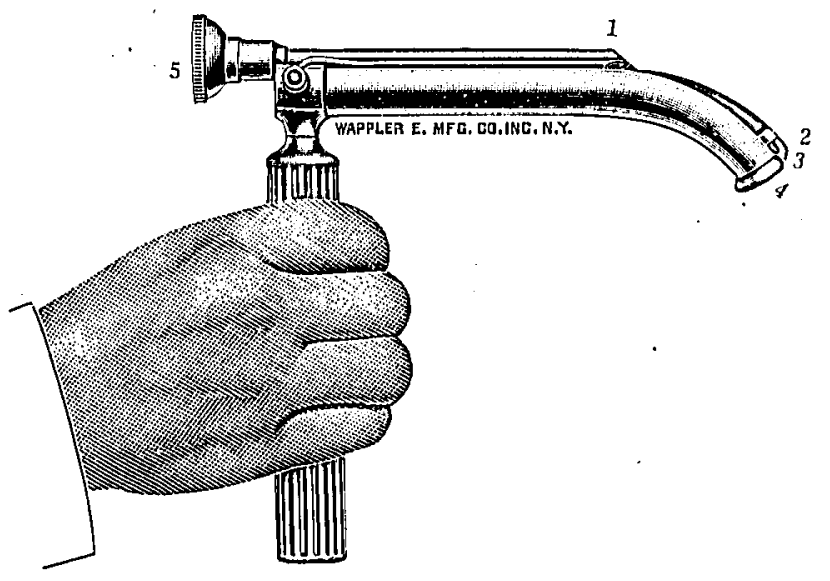

Figure 1. Indirect speculum for catheterizing the trachea, 1. Prism. 2. Lamp. 5. Objective glass through which the eye of the observer views the larynx in the direction of $3-4$.

- difficult. The rectum also must be carefully cleaned beforehand. Under usual conditions and with expert care irritation of the rectum is rarely produced. Cunningham, Leggett and Sutton have laid down the principles and developed the technic to a high point of efficiency.

Intra-venous anesthesia, only recently experimented with in this country, fulfills somewhat the same indications as rectal anesthesia.

To Dr. Francis Itonan belongs much of the credit for developing in this country a successful technic for the administration of intravenous anesthesia.

With both rectal and intravenous anesthesia the surgeon must rely entirely upon the patient's position in order to protect the 
trachea from the inhalation of blood and mucus and it is absolutely important to provide for free expiration in order to regularly eliminate the ether.

In contrast, however, to all these methods, anesthesia by intratracheal insufflation, i. e. through a tube introduced into the trachea, meets the requirements of the nose, throat and oral surgeon in an eminently satisfactory manner. Either ether or nitrous oxid and oxygen may be used as the anesthetic. With a minimum of effort on the part of the anesthetist, a perfectly even anesthesia is produced with complete relaxation of the patient and the maintenance of a rosy color. This statement is as true of nitrous oxid and oxygen, assuming that the patient is a normal individual, as it is of ether. In fact intra-tracheal anesthetization by both ether and

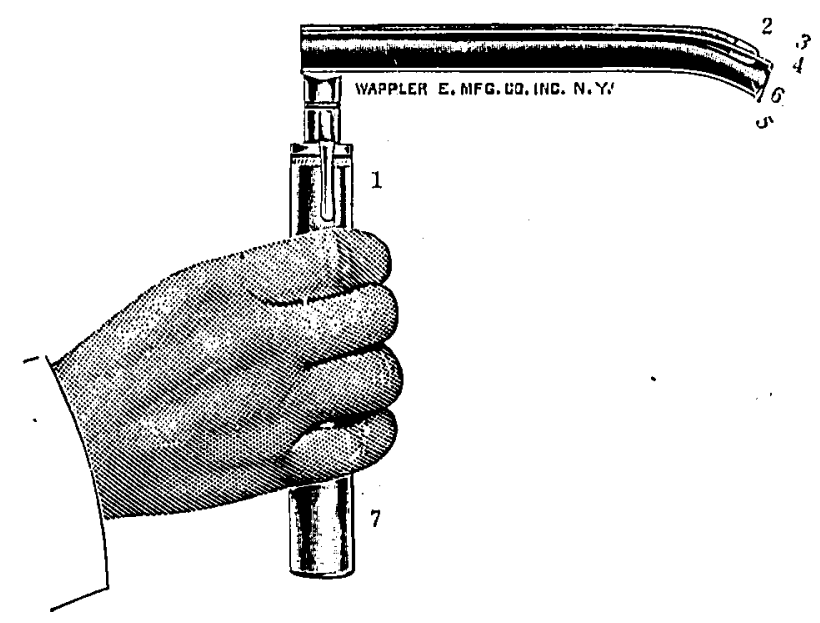

Figure 2. Direct speculum for catheterizing the trachea. 1. Press button for illuminating the lamp 2. Lamp. 3-4. Direction of vision. 5-6. Direction taken by the catheter. 7. Handle contalning two dry cells.

nitrous oxid renders possible a better and more complete anesthesia that can be obtained by either of these anesthetics when administered in the ordinary manner. It is, therefore, questionable whether intra-tracheal anesthesia should not be ustd very generally.

The only drawback to intra-tracheal anesthesia is the difficulty sometimes experienced in inserting the intra-tracheal catheter. To the expert laryngologist it may seem that catheterization of the trachea should always be a simple matter. In the fully relaxed patient it is frequently an easy matter to pass a rubber catheter into the trachea with the fingers alone. In many patients, fully relaxed, the larynx can be seen and catheterized without even flex- 
ing the head by the aid of the Jackson direct laryngoscope after the manner described by Dr. Richard Johnston of Baltimore.

The most reliable method of all is by means of the Jackson direct laryngoscope with the head in extreme extension. Even if simpler methods were as uniformly successful, the use of the direct laryngoscope in this manner would be preferable for the very important

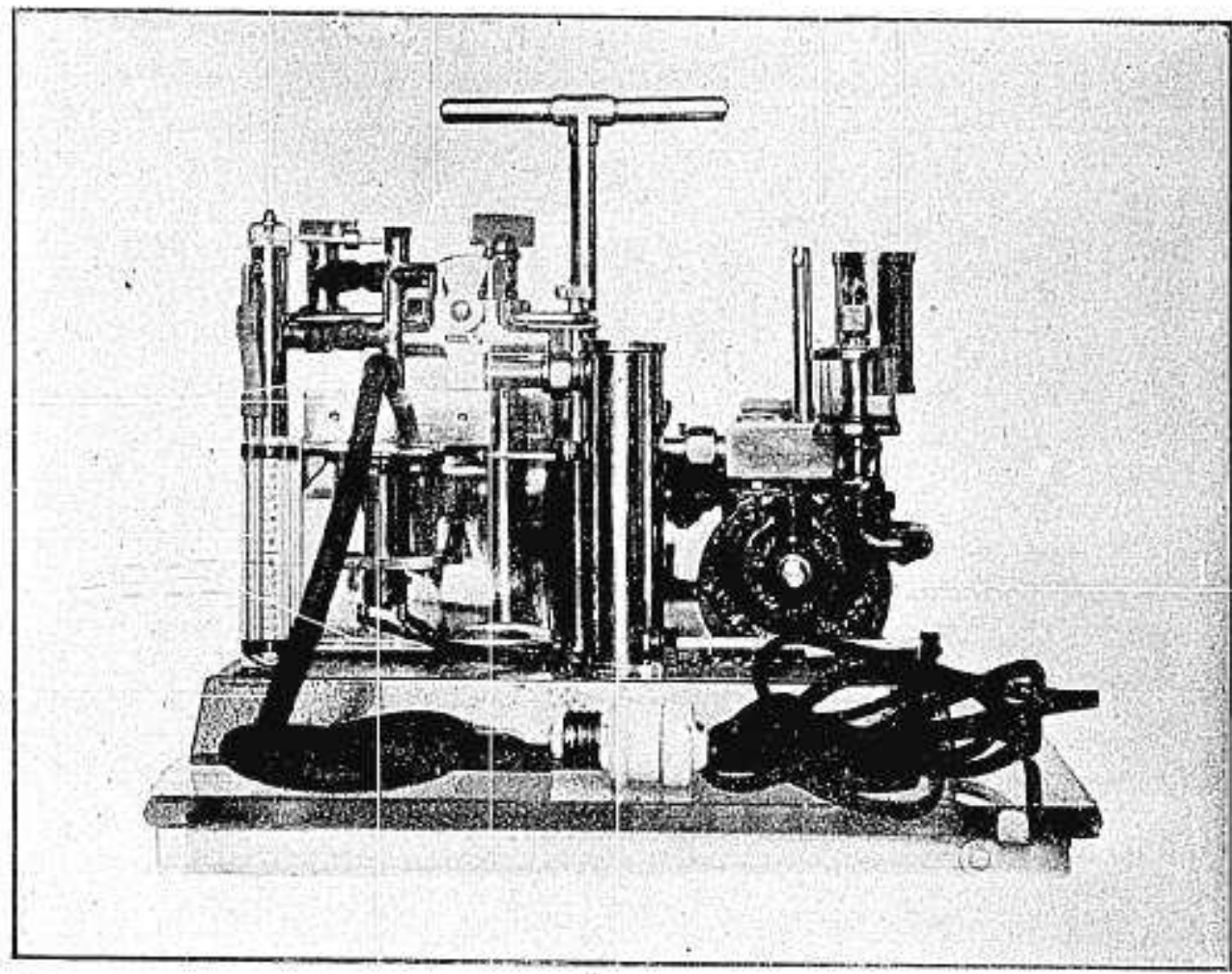

Figure 3. Apparatus for administering intra-tracheal ether anesthesia. It measures $12 \times 14$ inches and weighs 28 pounds. 1. Rotary blower; 2 . Over the position of the motor which is lidden behind the ether jar. 3. Alr filter and mufler into which the air passes from the blower 4 sjide valve through which the alr passes from the filter. It shunts any desired portion of the air from passing through the ether jar. 5. Ether jar. 6. Water jar, containing an electric heater for warming and moistentng the current
of ar. 7. Intercupting slice valve operated by a worm wheel in the posiof air. 7 . Interrupting slide vilve operated by a worm wheel in the position inclicated by the arrow " 3 ," but hidden in the picture behind the any desired pressure. 10. Manometer. 11. Rubber tube conducting the air to the patient.

reason that it permits of inspection of the larynx before the insertion of the catheter. Dr. Chevalier Jackson has called the writer's attention to one death already attributable to intra-tracheal anesthesia because of failure to previously inspect the larynx.

Not a little trouble has been experienced, however, in the intro- 
ing the head by the aid of the Jackson direct laryrgoscope after the manner described by Dr. Richard Jehnston of Baltimore.

The most reliable method of all is by means of th: Jacksøn direct laryngescope with the hear in extreme extension. Even if simpler methøds were as uniformly successful, the use of the direct laryncoscope in this manner would be preferable for the very impertant

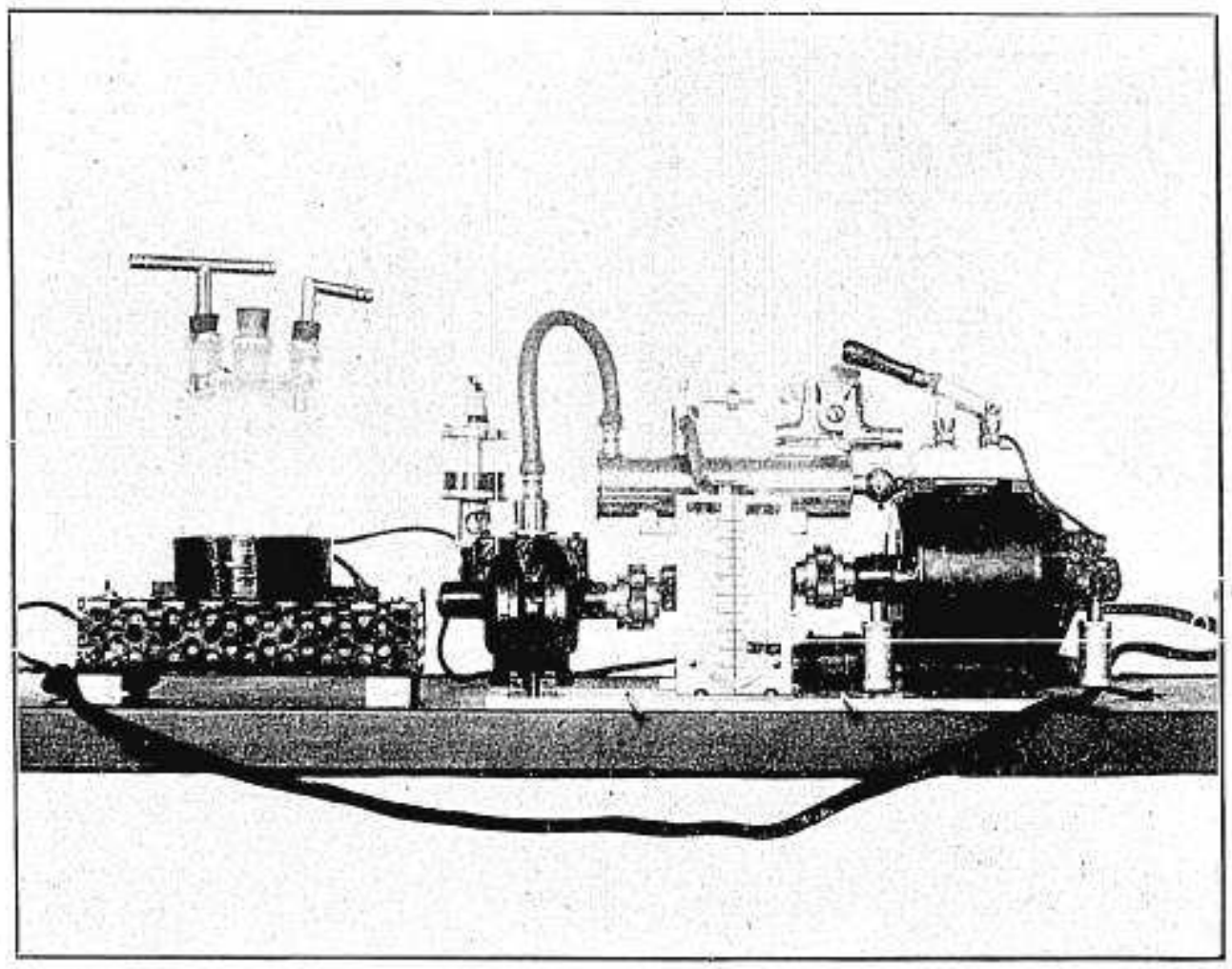

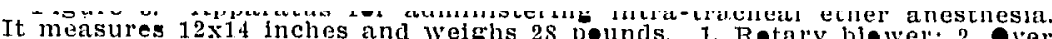
the position of the mer and muller int which the alr passes fram the other far. 3 , All filter threugh which the ale passes frem the fitel. tion of the ir from passing thertion of the air from. passing through the ether jar. 5. Fther jar. 6. Water Jar, containing an electric heater for warming and moistening the current of air. 7. Interrupting slfie valve eperated by a welm wheel in the pesitien indleated $b y$ the allow "g," but hidden in the picture behind the blower" "I." S. Air pressure safety valve which can be set te blew off at aiv desired pressure, 16. Manomeler. 11. Rubber tube conducting the air to the patient.

reasen that it perinits of inspection of the larynx before the insertion of the catheter. Dr. Chevalier Jackson has called the writer's attention to one death already attributable to intra-tracheal anesthesia because of failure to previeusly inspect the larynx.

Nøt a little trouble has been experienced, however, in the intrø- 
ing the head by the aid of the Jackson direct laryngoscope after the manner clescribed by Dr. Richard Jehnston of Raltimere.

The most reliable methed of all is by means of the Tackson direct laryngoscope with the head in extreme extension. Even if simpler methods were as uniformly successful, the use of the direct laryngoscope in this manner would be preferable for the very important

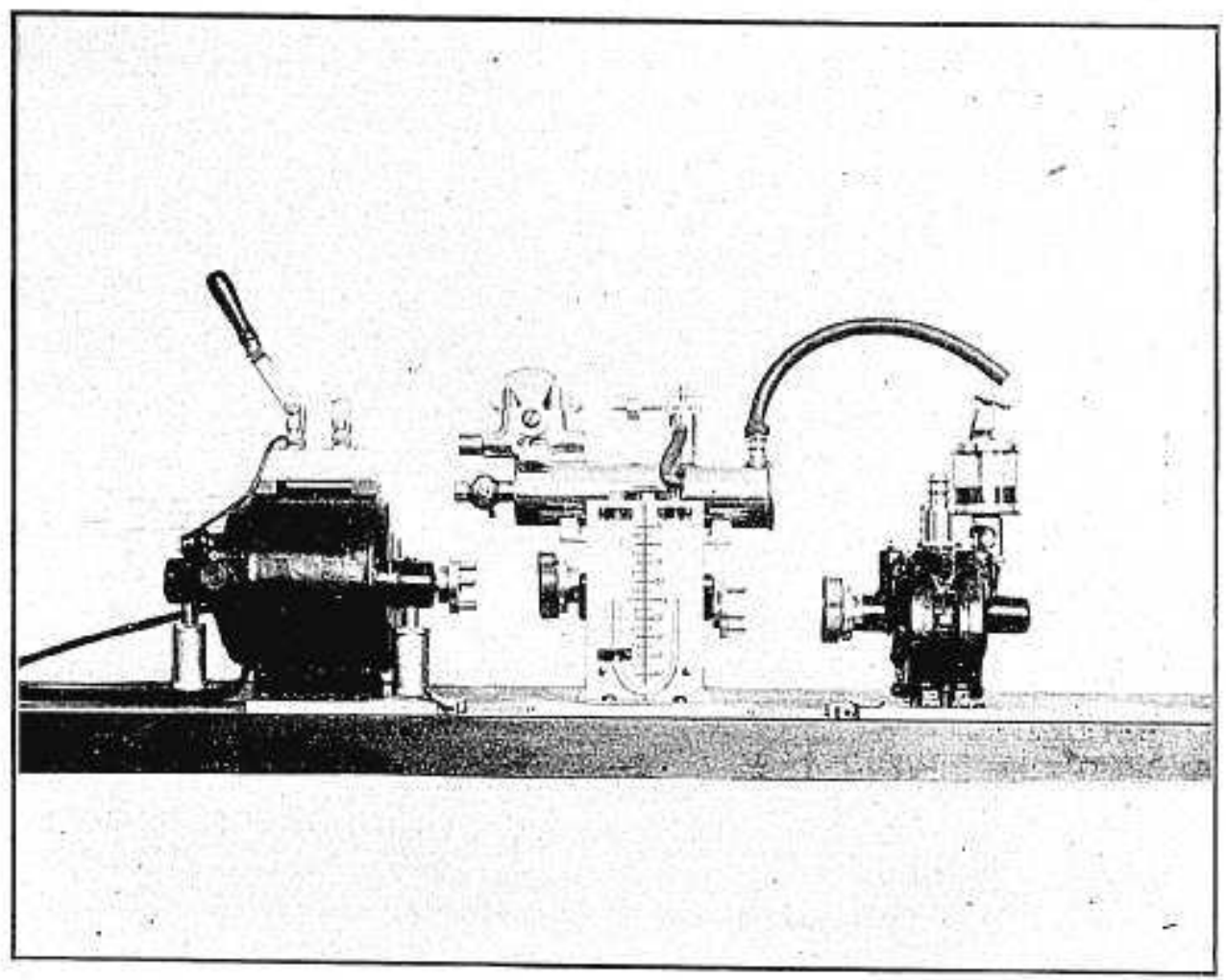

the position or the moter which is lifden behind the ether jar. 3, Alr fiter and muffer inte which the air passes frem the blower. 4. Slide valve through which the alr passes from the filter. It shunts any desired portion of the air from passing through the ether jar. 5. Dither jar. 6. Water far, containing an electric lieater for warming and moistentng the current of air. 7. Interrupting slite valve eperated by a werm whel in the pesition indicated by the arrow " 9 ," but hidden in the picture behind the blower" " $I . " S$, Air pressure safecy valve which can be set to blow of any desired pressure. 16. Mnometer. 11. Rubber tube conducting the air to the patient

reason that it permits of inspection of the larynx before the insertion of the catheter. Dr. Chevalier Jackson has called the writer's attention to one death already attributable to intra-tracheal anesthesia becattse of frilure to previously inspect the larynx.

N॰t a little trøuble has been experienced, høwever, in the intrø- 
curved upper half of the speculum and through its central notch which serves to keep the catheter in the middle line, Figure " 2 ."

'This control of the distal end of the catheter even though it causes only a slight forward bend of the catheter offers a very great advantage. It permits of easy catheterization of the larynx even when the patient's pharyngeal reflexes are not completely abolisherl and without the necessity for the same degree of extension of the head. The omission of the telescope greatly simplifies the instrument, while the possibility of viewing the larynx directly is superior to viewing it inclirectly, even though the latter method permits of a greater curve in the distal end of the catheter.

The illumination is obtained through a lamp placed at " 2 ," which is lighted through two small storage cells contained in the handle of the instrument.

With this instrument, a large size of catheter $3 / 8$ of an inch in diameter designed for intra-tracheal anesthesia by nitrous oxid and oxygen may easily be introduced into the larynx.

As soon as the tube has been introduced its external extremity is connected with the tube from the insufflation apparatus; and from this time on, that is before the beginning of the operation, the anesthetist may take his position at any convenient distance from the patient and the operator is unhindered by his presence or by an anesthetizing apparatus other than the tube emerging from between the patient's teeth. 'This tube, for mouth operations, is best held in place by an assistant who also manages the mouth-gag and retractors, for then it may be moved at will to any portion of the mouth not within the field of operation. For other operations, a small metal tube, one inch long, may be slipped over it between the teeth. This is kept from slipping out of the mouth by a spring which passes behind the neck somewhat in the same manner as a frame truss which maintains its position by pressure around the back. Figure 3 and 4 represents the author's apparatuses designed for supplying the ether vapor to the intra-tracheal tube. There are several features about them which deserve emphasis even at the expense of repetition. Figure 3 represents an apparatus which may be described as an easily portable machine, weighing about 28 pounds and measuring $10 \times 12$ inches and capable of supplying a continuous current of warm, moistened air saturated with any desired amount of ether vapor. The current may be interrupted automatically for the purpose of allowing regular deflation of the lings.

"'hese features are all of some importance and contribute to the best resitts in anesthesia. The temperature of the air delivered at 
the end of a tube three feet long has been measured. It is 95 degrees, at least 15 to 30 degrees higher than a current of air coming directly from the ether bottle. It is also perceptibly moistened, and we are forced to believe that the every day experience of the evil effects of mouth-breathing makes it evident that warmed ether vapor mixed with moistened warm air approximate more closely to the normal physiological conditions and are better borne.

Next, concerning the amount of ether vapor. 'In the above apparatus it is possible to regulate the amount of ether in two ways, first by the slide valve " 4 " any portion of the current of air may be diverted from passing over the surface of the ether, second, by the cock handle " 12 " controlling the inlet valve to the ether flask, the percentage of ether vapor in the current of air may be increased over an amount which it is possible to pick up by simply passing the air over the surface of the ether by bubbling a portion of this air through the top layers of the ether. This additional quantity is sometimes needed with alcoholic patients.

Finally as regards the interruptions. By laboratory experiment there seems to be no change in the sphymographic tracings of the pulse produced by regularly interrupting the current of air supplied during intra-tracheal anesthesia when the anesthesia is administered within the limits of the proper pressures for intratracheal anesthesia. Very serious diminution of the volume output of the heart is produced by higher pressures. The greatest benefit obtained by interrupting the current of air is the effect of such interruptions when regularly and automatically performed upon respiration. The author possesses tracings which demonstrate the almost entire abolition of efforts at respiration caused by interrupting the current of air during intra-tracheal anesthesia. Such a condition renders the anesthesia far safer and does much, not only to conserve the expenditure of energy by the patient, but the ease of operating for the surgeon. In this apparatus only the physiological effect upon the patient is depended upon as the guide to the correct percentage of ether to use. Such is a safe guide, though Dr. Connell has rendered surgeons a service in defining the correct percentages and showing how closely definite percentages can be followed.

Figure 4 represents an apparatus which is still smaller and, therefore, more portable. It weighs only $18 \mathrm{lbs}$. and measures $4 \mathrm{t} / 2 \mathrm{x} 5 \mathrm{x} 5$ inches. By removing the two pins penetrating the base plate the apparatus will come apart in three pieces as illustrated in Figure 5 and may then be packed in a small hand-bag. This smaller ap- 
paratus is most simple in. construction. It contains the same size blower and motor as the apparatus figured in Figure 3 and only differs from the latter in not running quite so noiselessly and in not being provided with so serviceable a means for interrupting and warming and moistening the current of air.

Actual trial with this apparatus during a period of eight months has given uniformly good results. In the majority of cases in which the writer has used the apparatus there have been some special indications for it. Five have been intra-thoracic cases and, in most of the other cases, the operations were within the nose, mouth or about the head. It has given all the advantages which have been claimed for intra-tracheal insufflation. The operations were conducted without interference from the anesthetist or his apparatus and the anesthesia was smooth and uninterrupted. On no occasion was there any inconvenience from blood or mucus in the throat. During the past two years the writer has made a considerable number of esophagoscopic and gastroscopic examinations. 'These he ustally conducts under local anesthesia, but for a complete gastroscopic examination it is desirable to give a general anesthetic. The ease of making these examinations with the smooth uninterrupted anesthesia produced by the intra-tracheal anesthesia contrasted strongly with similar examinations conducted under anesthesia produced by inhalation through the mouth.

Bronchoscopic examinations and operations may similarly be performed under intra-tracheal anesthesia-a small catheter may be inserted by the side of the bronchoscopic tube, or the insufflation anparatus may be connected directly to the bronchoscopic tube and the ether vapor administered intermittently.

In fact, it is interesting to note that a number of years ago Dr. Chevalier Jackson availed himself of true intra-tracheal insuffation and at the suggestion of T. Drysdale Buchanatu added an auxilliary ether tube to his bronchoscope.

In conclusion, for the longer operations of the nose, throat and oral surgeon, intra-tracheal anesthesia meets the indications in a manner that no other form of anesthesia does.

The technic of nitrous oxid and oxygen by intra-tracheal insufflation differs considerably from ether anesthesia and will be described in another commtnication.

104 East Fortieth Street. 